\title{
Society - Totally Dependent Upon ICT? Introduction to the CIP-2010 Conference Proceedings
}

\author{
William Caelli \\ Information Security Institute, Queensland University of Technology, GPO Box 2434, \\ Brisbane, Queensland, 4001, Australia \\ w.caelli@qut.edu.au
}

At the $50^{\text {th }}$ anniversary of the formation of the International Federation for Information Processing the simple fact that national economies and international commerce alike have become totally dependent upon the reliable and secure operation of national and global information infrastructures has been accepted. Moreover, the realization that societies are moving towards so-called "digital economies" has been acknowledged by all, from the citizen to the highest leader of a nation. From the early days of 1960, with a perceived competitive advantage through computer usage, to today's acknowledgement of total dependence upon computer systems and integrated data networks on a global scale, the realization that the emerging digital economy in nation states, as well as national security and societal well-being, depend upon necessary critical information infrastructures has been accepted by governments and all enterprises worldwide. From banking and finance systems to healthcare record maintenance to "e-Government" all societal activities are affected.

In particular the theme of this IFIP first CIP conference acknowledges that all basic or national critical infrastructures themselves, from electrical power systems to telecommunications structures to water/sewerage systems and so on, whether owned and operated by the public or private sector, depend fundamentally upon a national and critical information infrastructure. On a global scale the evidence is clear that nations as well as international enterprises of all natures in a global economy have moved to address this reality through relevant draft legislation, regulations, industry codes and the like.

At the same time there is recognition at the United Nations level that the rapid and almost unchecked rise of cybercrime is a reality and the concepts and reality of "information operations" and "cyber warfare" have been examined in recent years. Thus there is also recognition that imperatives for national defence have moved into cyberspace as well. Even topics related to the position of information assurance at national levels; the political, ethical and legal position related to the use of "information operations" and appropriate responses to detected "cyber-attack"; the problems of "hardening" national information infrastructures through public sector leadership and public/private sector cooperation and like themes are now topics discussed in the open media globally and almost daily.

The topic of CIIP, NIIP, NCI, or whatever term or anagram is used to describe this change, of necessity brings together the skills of computers scientists and mathematicians, engineers, information technologists and others to combine with the vital efforts of legal professionals, public and defence policy researchers, social 
scientists and psychologists, anthropologists, political scientists and related disciplines to address a common goal to provide effective and acceptable solutions to the growing threats.

CIP-2010 is a first and small attempt by IFIP to address these concerns with an emphasis on the international imperatives, in line with the very nature of IFIP itself. The papers in this small conference address current thinking and research in some aspects of these vital global concerns and demonstrate the varied nature of the problems identified, including the vital need for education and training efforts in the area. The conference presents a unique opportunity, at a time when nationally, regionally and internationally associated policies and legal regimes are under development, to both ponder those activities as well as to provide research leadership at both technical and policy levels. 